\title{
Association of angiogenic cytokines (VEGF-A and VEGF-C) and clinical characteristic in women with unexplained recurrent miscarriage
}

\author{
Bagheri $\mathrm{A}^{1}$, Kumar $\mathrm{P}^{2}$, Kamath $\mathrm{A}^{3}$, Rao $\mathrm{P}^{1}$ \\ Department of Biochemistry, Kasturba Medical College, Manipal University, Manipal - 576104, \\ Karnataka, India. azadehbagheri64@yahoo.com
}

\begin{abstract}
INTRODUCTION: Recurrent miscarriage (RM) defined as 2 or more spontaneous miscarriage before 20 weeks of gestation, affects at least $1 \%$ of couples trying to conceive. In over $50 \%$ of cases, the cause of the loss of pregnancy remains unexplained. Reduced expression of Angiogenic factors such as: vascular endothelial growth factor (VEGF-A) and VEGF-C has been linked with spontaneous miscarriage, likely due to defective foetal and placental angiogenesis.

AIMS AND OBJECTIVES: To investigate the relationships between serum level of VEGF-A and VEGF-C with clinical characteristic in women with URM and compare to pregnant and healthy women.

MATERIALS AND METHODS: A case-control study, which was conducted between 90 non-pregnant women with history of RM, age-matched with 70 non-pregnant women without history of recurrent abortion with at least one child (controls) and 70 pregnant women without history of recurrent abortion with at least one child (controls). Those with unexplained RM were eligible. Demographic and Anthropometric data were retrieved by pre-test questionnaire and serum level of VEGF-A and VEGF-C measured by ELISA kit.

RESULTS: This study showeds that maternal levels of VEGF-A and VEGF-C were distinctly lower in RSA (189.87 \pm 88.1 vs $238.8 \pm 99.6)$ compared to healthy (239.1 \pm 99.7 vs $275.5 \pm 133.08)$ and pregnant $(301.5 \pm 76.4$ vs 402.5 \pm 128.6 ) women as control groups. Univariate analysis demonstrated that clinical characteristic factors were significantly associated with concentration of VEGF-A and VEGF-C in cases and controls.

CONCLUSIONS: Our findings suggest that these molecules could be used as potential predictive markers of miscarriage in these women presenting with URM (Tab. 4, Fig. 5, Ref. 40). Text in PDF www.elis.sk.

KEY WORDS: recurrent miscarriage, VEGF-A, VEGF-C, Age, BMI.
\end{abstract}

\section{Introduction}

Angiogenesis is one of the essential molecular procedures in the female reproductive system (1). The interaction between the endometrium and the trophectodermal cells of the blastocyst is one of the crucial moments for the beginning and maintenance of successful pregnancy (2). In cases of deregulation, different pathologies in human reproduction could be presented such as: recurrent implantation failures, recurrent miscarriages (RM) or endometriosis $(3,4)$.

The American Society of Reproductive Medicine (ASRM) defined recurrent miscarriage (RM) as two or more failed clinical

${ }^{1}$ Department of Biochemistry, Kasturba Medical College, Manipal University, Manipal - 576104, Karnataka, India, ${ }^{2}$ Department of Obstetrics \& Gynecology, Kasturba Medical College, Manipal University, Manipal 576104, Karnataka, India, ${ }^{3}$ Department of Community Medicine, Kasturba Medical College, Manipal University, Manipal - 576104, Karnataka, India

Address for correspondence: A. Bagheri, Department of Biochemistry, Kasturba Medical College, Manipal University, Manipal - 576104, Karnataka, India. pregnancies as documented by ultrasonography or histopathologic examination (5). It affects $1-5 \%$ of all couples trying to conceive $(6,7)$. The commonly accepted definition stipulates that the foetus or embryo should weigh $500 \mathrm{~g}$ or less, a stage that corresponds to a gestational age of up to 20 weeks (8). Although many different factors related to RM, including chromosomal, anatomical and endocrine aberrations, and infection, have been investigated, $50 \%$ of RM cases are still without identifiable factors and labelled as unexplained (unexplained RM) (8). It's been proposed that URM belongs to an autoimmune illness associated with the failure of foetal-maternal immunologic tolerance (9).

Vascular endothelial growth factor (VEGF) (1), also known as vascular permeability factor (VPF), is an important angiogenetic cytokine. VEGF regulates proliferation, differentiation, and survival of endothelial cells and enhances vascular permeability (11). VEGF-A consists of at least six isoforms through alternative splicing in humans $(121,145,165,183,189$, and 206 amino acids), which have different biological properties and bioavailability (12). VEGF functions are mediated via binding to its tyrosine kinase receptors; VEGF receptor 1 (VEGFR1/Flt1) and VEGF receptor 2 (VEGFR2/Flk1/KDR). Expression of VEGF-A 
and VEGF-C has been demonstrated in the human endometrium throughout the menstrual cycle with an increase in the late proliferative and secretory phases $(13,14)$. In addition, VEGF's expression was found in decidual cells of early pregnancy (15). On the other hand, expression of VEGF receptors was shown in human endometrium (13).

Dysregulation in VEGF-C production at the maternal-foetal interface could be a signal for poor angiogenesis and pregnancy complications. Reduced expression of VEGF-C has been reported in pregnancies experiencing intrauterine growth restriction and preeclampsia. Involvement of VEGF-C may thus explain the non-killer phenotype of uNK cells despite possessing toxic granules and expressing cytotoxicity receptors. Satyan S, in 2009 (16) proved that vascular endothelial growth factor (VEGF)C, a proangiogenetic factor produced by uNK cells, is responsible for their noncytotoxic activity. Peripheral blood NK cells fail to produce VEGF-C and remain cytotoxic. This response can be reversed by exogenous VEGF-C and it deals with the growth of blood vessels and lymphatics (17).

On the other hand, in RM with increasing numbers of previous miscarriages comes an increasing risk of losing the next pregnancy. Kupka et al (18) found a miscarriage rate of $21 \%$ in couples with no previous miscarriage, in comparison with $27 \%$ with a single previous loss, and $31 \%$ with three previous losses. In addition, the age of women with RM will influence the findings in studies of endocrinological and nongenetic immunological biomarkers (19). Immune parameters such as: production of autoantibodies and T helper 2 cytokines are affected both directly by improved expectant mothers age. Also, it has been reported that maternal obesity and BMI (Body Mass Index) is associated with an increased risk of recurrent miscarriage after spontaneous and assisted conception (20).

Given these data, in the present study, we intend to discuss the association of angiogenetic cytokines (VEGF-A and VEGF-C) and to correlate Demographic and Anthropometric factors in patients with the history of unexplained recurrent miscarriage (URM) and compare the first trimester of pregnant and healthy women.

\section{Materials and methods}

Subjects

Were recruited subjects after an informed consent for this prospective cross sectional study. These were 90 non-pregnant women with history of URM and at least 2 pregnancy losses before 20 weeks of gestation (cases), age matched with 70 non-pregnant women without history of recurrent abortion with at least one child and 70 pregnant women without history of recurrent abortion with at least one child (controls). Women were excluded in case of being positive for Antiphospholipid Antibody (APLA), anatomical factors for losses, endocrine abnormalities, couple with Karyotype abnormalities, Multiple Pregnancy, pathologic hyperlipidemia, hepatic or pulmonary and renal diseases, anaemia and coagulopathies.

The cases were selected at the Obstetrics and Gynaecology Department and Manipal Assisted Reproduction Centre (MARC) of the Manipal University. Ethical approval was obtained from the University of Manipal, Ethical Board.

\section{Collection of blood}

$5 \mathrm{ml}$ of venous blood sample was dispensed into ethylene diamine tetra-acetic acid (EDTA) tubes for the estimation of angiogenetic cytokines (VEGF-A and VEGF-C). The samples were then centrifuged at $500 \mathrm{~g}$ for $5 \mathrm{~min}$ to obtain plasma and serum respectively, and stored at $-20^{\circ} \mathrm{C}$ until analysis.

\section{Demographic characteristics}

Semi structured pre-test questionnaire was completed by each subject in order to obtain demographic data. The demographic characteristics tested were age and age at menarche (AM), length of menstrual cycle (LMC), number of previous miscarriage (NPM), number of previous pregnancies (NPP) and number of live birth(s) (NLB).

\section{Anthropometric characteristics}

The anthropometric parameters measured were weight, height, body mass index (BMI). BMI was used as an indicator of obesity,

Tab. 1. Description of all parameters in cases and controls groups.

\begin{tabular}{|c|c|c|c|c|c|c|c|c|}
\hline & & \multirow[t]{2}{*}{$\mathrm{n}$} & \multirow[t]{2}{*}{ Mean } & \multirow[t]{2}{*}{ SD } & \multicolumn{2}{|c|}{$95 \%$ Confidence interval for mean } & \multirow[t]{2}{*}{ Mini } & \multirow[t]{2}{*}{ Max } \\
\hline & & & & & Lower Bound & Upper Bound & & \\
\hline \multirow{4}{*}{$\begin{array}{l}\text { VEGF-A } \\
(\mathrm{pg} / \mathrm{ml})\end{array}$} & URM & 90 & 189.875 & 88.1672 & 171.4092 & 208.3417 & 54.32 & 463.72 \\
\hline & HEALTHY & 70 & 239.103 & 99.7780 & 215.3119 & 262.8944 & 106.32 & 670.43 \\
\hline & PREGNANT & 70 & 301.572 & 76.4535 & 283.3424 & 319.8018 & 155.43 & 700.21 \\
\hline & Total & 230 & 238.852 & 99.63577 & 225.9075 & 251.7974 & 54.32 & 700.21 \\
\hline \multirow{4}{*}{$\begin{array}{l}\text { VEGF-C } \\
(\mathrm{pg} / \mathrm{ml})\end{array}$} & URM & 90 & 209.902 & 99.23208 & 189.1187 & 230.6862 & 87.32 & 670.43 \\
\hline & HEALTHY & 70 & 275.557 & 133.0853 & 243.8243 & 307.2905 & 78.32 & 1001.32 \\
\hline & PREGNANT & 70 & 402.506 & 128.6099 & 371.8402 & 433.1721 & 150.21 & 900.32 \\
\hline & Total & 230 & 288.5029 & 143.5256 & 269.8557 & 307.1502 & 78.32 & 1001.32 \\
\hline \multirow{4}{*}{$\begin{array}{l}\mathrm{BMI} \\
\left(\mathrm{kg} / \mathrm{m}^{2}\right)\end{array}$} & URM & 90 & 27.8207 & 7.28099 & 26.2957 & 29.3456 & 14.72 & 44.02 \\
\hline & HEALTHY & 70 & 24.9033 & 6.17487 & 23.4309 & 26.3756 & 15.88 & 44.22 \\
\hline & PREGNANT & 70 & 24.1539 & 5.98971 & 22.7257 & 25.5821 & 15.47 & 37.51 \\
\hline & Total & 230 & 25.8168 & 6.75133 & 24.9396 & 26.6939 & 14.72 & 44.22 \\
\hline \multirow{3}{*}{$\begin{array}{l}\text { AGE } \\
\text { (years) }\end{array}$} & URM & 90 & 30.6667 & 6.34230 & 29.3383 & 31.9950 & 21.00 & 45.00 \\
\hline & HEALTHY & 70 & 28.9571 & 5.86425 & 27.5589 & 30.3554 & 18.00 & 47.00 \\
\hline & Total & 230 & 29.5304 & 6.15353 & 28.7310 & 30.3299 & 2.00 & 47.00 \\
\hline
\end{tabular}


Tab. 2. Correlations of parameters in women with history of Unexplained Recurrent Miscarriage.

\begin{tabular}{|c|c|c|c|c|c|c|c|c|}
\hline & & $\begin{array}{l}\text { VEGF-A } \\
(\mathrm{pg} / \mathrm{ml})\end{array}$ & $\begin{array}{l}\text { VEGF-C } \\
(\mathrm{pg} / \mathrm{ml})\end{array}$ & $\begin{array}{c}\text { BMI } \\
\left(\mathrm{kg} / \mathrm{m}^{2}\right)\end{array}$ & $\begin{array}{c}\text { AGE } \\
\text { (years) }\end{array}$ & $\begin{array}{l}\text { Number of previse } \\
\text { miscarriage (NPM) }\end{array}$ & $\begin{array}{l}\text { Age at menarche } \\
\text { (AM) }\end{array}$ & $\begin{array}{c}\text { Length of menstrual } \\
\text { cycle (LMC) }\end{array}$ \\
\hline \multirow[t]{2}{*}{ VEGF-A (pg/ml) } & Pearson Correlation & 1 & $.584 * *$ & $-.208 *$ & $-.557 * *$ & $-.451 * *$ & -.153 & $-.407 * *$ \\
\hline & Sig. (2-tailed) & & .000 & .049 & .000 & .000 & .150 & .000 \\
\hline \multirow[t]{2}{*}{ VEGF-C (pg/ml) } & Pearson Correlation & $.584 * *$ & 1 & $-.270 *$ & $-.231 *$ & -.079 & -.061 & -.137 \\
\hline & Sig. (2-tailed) & .000 & & .010 & .028 & .461 & .570 & .197 \\
\hline \multirow[t]{2}{*}{ BMI $\left(\mathrm{kg} / \mathrm{m}^{2}\right)$} & Pearson Correlation & $-.208 *$ & $-.270 *$ & 1 & .165 & .015 & -.113 & .081 \\
\hline & Sig. (2-tailed) & .049 & .010 & & .120 & .885 & .287 & .446 \\
\hline \multirow[t]{2}{*}{ AGE (years) } & Pearson Correlation & $-.557 * *$ & $-.231 *$ & .165 & 1 & $.758 * *$ & $.457 * *$ & $.495 * *$ \\
\hline & Sig. (2-tailed) & .000 & .028 & .120 & & .000 & .000 & .000 \\
\hline \multirow{2}{*}{$\begin{array}{l}\text { Number of previse } \\
\text { miscarriage (NPM) }\end{array}$} & Pearson Correlation & $-.451 * *$ & -.079 & .015 & $.758 * *$ & 1 & $.607 * *$ & $.642 * *$ \\
\hline & Sig. (2-tailed) & .000 & .461 & .885 & .000 & & .000 & .000 \\
\hline \multirow{2}{*}{$\begin{array}{l}\text { Age at menarche } \\
\text { (AM) }\end{array}$} & Pearson Correlation & -.153 & -.061 & -.113 & $.457 * *$ & $.607 * *$ & 1 & $.422 * *$ \\
\hline & Sig. (2-tailed) & .150 & .570 & .287 & .000 & .000 & & .000 \\
\hline \multirow{2}{*}{$\begin{array}{l}\text { Length of menstrual } \\
\text { cycle (LMC) }\end{array}$} & Pearson Correlation & $-.407 * *$ & -.137 & .081 & $.495 * *$ & $.642 * *$ & $.422 * *$ & 1 \\
\hline & Sig. (2-tailed) & .000 & .197 & .446 & .000 & .000 & .000 & \\
\hline TOTAL & $\mathrm{n}$ & 90 & 90 & 90 & 90 & 90 & 90 & 90 \\
\hline
\end{tabular}

** Correlation is significant at the 0.01 level (2-tailed)

* Correlation is significant at the 0.05 level (2-tailed)

Tab. 3. Correlations of parameters in Pregnant women.

\begin{tabular}{llcccc}
\hline & & VEGF-A $(\mathrm{pg} / \mathrm{ml})$ & VEGF-C $(\mathrm{pg} / \mathrm{ml})$ & BMI $\left(\mathrm{kg} / \mathrm{m}^{2}\right)$ & AGE $(\mathrm{years})$ \\
\hline VEGF-A $(\mathrm{pg} / \mathrm{ml})$ & Pearson Correlation & 1 & $.344^{* *}$ & -.167 & $-.304^{*}$ \\
& Sig. (2-tailed) & & .004 & .168 & .010 \\
\hline VEGF-C $(\mathrm{pg} / \mathrm{ml})$ & Pearson Correlation & $.344^{* *}$ & 1 & $-.359^{* *}$ & $.374^{* *}$ \\
& Sig. (2-tailed) & .004 & & .002 & .001 \\
\hline BMI $\left(\mathrm{kg} / \mathrm{m}^{2}\right)$ & Pearson Correlation & -.167 & $-.359^{* *}$ & $.287^{*}$ \\
& Sig. (2-tailed) & .168 & $-.374^{* *}$ & $.287^{*}$ & .016 \\
\hline AGE (years) & Pearson Correlation & $-.304^{*}$ & .010 & .016 & 1 \\
& Sig. (2-tailed) & 70 & 70 & 70 & 70 \\
\hline TOTAL & $\mathrm{n}$ & & & \\
\hline
\end{tabular}

** Correlation is significant at the 0.01 level (2-tailed)

* Correlation is significant at the 0.05 level (2-tailed)

Tab. 4. Correlations of parameters in Healthy women.

\begin{tabular}{|c|c|c|c|c|c|}
\hline & & VEGF-A(pg/ml) & VEGF-C $(\mathrm{pg} / \mathrm{ml})$ & $\operatorname{BMI}\left(\mathrm{kg} / \mathrm{m}^{2}\right)$ & AGE(years) \\
\hline VEGF-A (pg/ml) & $\begin{array}{l}\text { Pearson Correlation } \\
\text { Sig. (2-tailed) }\end{array}$ & 1 & $\begin{array}{c}.785^{* *} \\
.000 \\
\end{array}$ & $\begin{array}{c}-.248^{*} \\
.039 \\
\end{array}$ & $\begin{array}{c}-.413^{* *} \\
.000 \\
\end{array}$ \\
\hline VEGF-C (pg/ml) & $\begin{array}{l}\text { Pearson Correlation } \\
\text { Sig. (2-tailed) }\end{array}$ & $\begin{array}{c}.785^{* *} \\
.000 \\
\end{array}$ & 1 & $\begin{array}{l}-.312^{* *} \\
.008 \\
\end{array}$ & $\begin{array}{c}-.324 * * \\
.006 \\
\end{array}$ \\
\hline$\overline{\mathrm{BMI}\left(\mathrm{kg} / \mathrm{m}^{2}\right)}$ & $\begin{array}{l}\text { Pearson Correlation } \\
\text { Sig. (2-tailed) }\end{array}$ & $\begin{array}{c}.248^{*} \\
.039 \\
\end{array}$ & $\begin{array}{c}-.312 * * \\
.008 \\
\end{array}$ & 1 & $\begin{array}{l}.050 \\
.679 \\
\end{array}$ \\
\hline$\overline{\mathrm{AGE} \text { (years) }}$ & $\begin{array}{l}\text { Pearson Correlation } \\
\text { Sig. (2-tailed) }\end{array}$ & $\begin{array}{c}-.413 * * \\
.000 \\
\end{array}$ & $\begin{array}{c}.324 * * \\
.006 \\
\end{array}$ & $\begin{array}{l}.050 \\
.679 \\
\end{array}$ & 1 \\
\hline TOTAL & $\mathrm{n}$ & 70 & 70 & 70 & 70 \\
\hline
\end{tabular}

** Correlation is significant at the 0.01 level (2-tailed)

* Correlation is significant at the 0.05 level (2-tailed)

and subjects were stratified into the five groups based on World Health Organization classification as underweight $(<18.5 \mathrm{~kg} /$ $\mathrm{m}^{2}$ ), normal $\left(18.5-24.9 \mathrm{~kg} / \mathrm{m}^{2}\right)$, overweight $\left(25-29.9 \mathrm{~kg} / \mathrm{m}^{2}\right)$, and obese $\left(\geq 30 \mathrm{~kg} / \mathrm{m}^{2}\right)$.

\section{Biochemical characteristics}

VEGF-A and VEGF-C were analysed with enzyme-linked immunosorbent assay (ELISA) kits (all manufactured by R\&D Systems, Minneapolis, MN).VEGF-A and VEGF-C quantified with an ELISA that measures the extracellular (soluble) domain of VEGFR-2 and VEGFR-1. No cross-reactivity or interference was detected between the two receptors in the ELISA assays. All ELISA assays were run under Good Laboratory Practice conditions, and performance specifications of each ELISA were validated for their intended purpose, as per established guidelines and read at $450 \mathrm{~nm}$ immediately.

\section{Statistical analysis}

Where appropriate, the data were expressed as the mean \pm SD. The statistical analysis was conducted using the SPSS Statis- 
tical Package version 23, (Chicago, IL, USA) employed for the analyses of data. Student's $\mathrm{t}$-test was used for the comparison of quantitative variables. Pearson's n correlation coefficient was used for the relationship between quantitative variables. $\mathrm{P}<0.05$ was regarded as significant.

\section{Results}

There were 90 non-pregnant women with a history of URM and at least 2 pregnancy losses before 20 weeks of gestation (cases), age matched with 70 non-pregnant women without history of recurrent abortion with at least one child and 70 pregnant women without history of recurrent abortion with at least one child (controls). The descriptive level of serum Angiogenetic cytokine (VEGF-A and VEGF-C), Age and BMI in patients and control groups are shown in (Tab. 1).

The correlation of serum level of VEGF-A and VEGF-C with Demographic and Anthropometric Characteristics in 90 non-pregnant women with history of URM (Tab. 2), with 70 non-pregnant women (Tab. 3) and 70 pregnant women without history of recurrent abortion with at least one child (Tab. 4). There was a
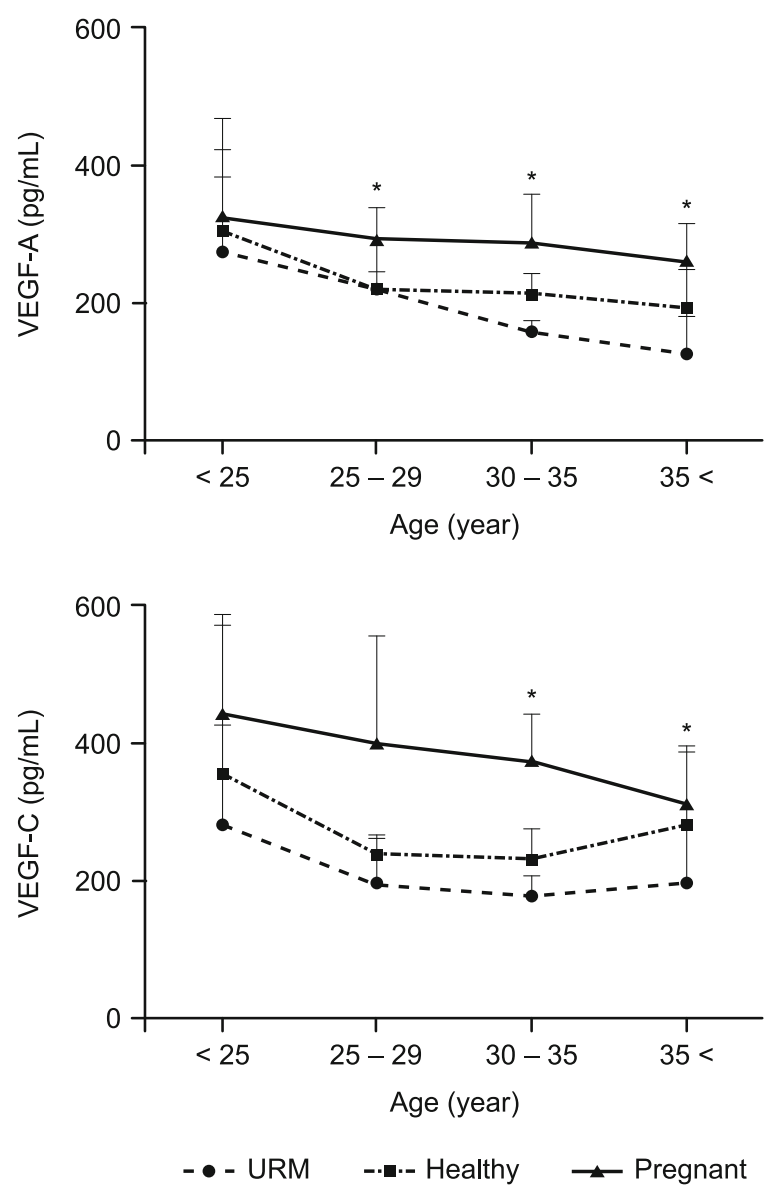

Fig. 1. Evaluation of angiogenetic factors (VEGF-A and VEGF-C) and comparing with age groups in women with unexplained recurrent miscarriage $(* \mathrm{p}<0.05)$. significant negative correlation with angiogenetic factors among the case and control groups with Age and BMI. Also, there was a significant negative correlation with VEGF-A among URM with a number of previous miscarriage and length of menarche. There was a strong positive correlation with concentration of VEGF-A and VEGF-C among all groups (Pearson correlation of VEGF-C and VEGF-C $=0.688, \mathrm{p}<0001)$.

We assessed whether VEGF-A and VEGF-C levels in women with a history of recurrent miscarriage compared to healthy and pregnant women was differed in Age (Fig. 1) and BMI groups (Fig. 2). The results showsed an increase in the estimated level VEGF-A and VEGF-C in young age groups when compared with the old age and decrease in the level of VEGF-A and VEGF-C in obese among all groups.

Multiple regression and final equation for VEGF-A and VEGF$\mathrm{C}$ among of patients and control groups showed a significant linear regression (R-Esq. $52.7 \%, \mathrm{p}<0.10$ ) (Fig. 3).

$\mathrm{ROC}$ analysis in the unexplained recurrent miscarriage group shows the area under the curve for VEGF-A. It is near 0.807 and cut point $200.17(\mathrm{pg} / \mathrm{ml})$ and for VEGF-C is near 0.872 and cut
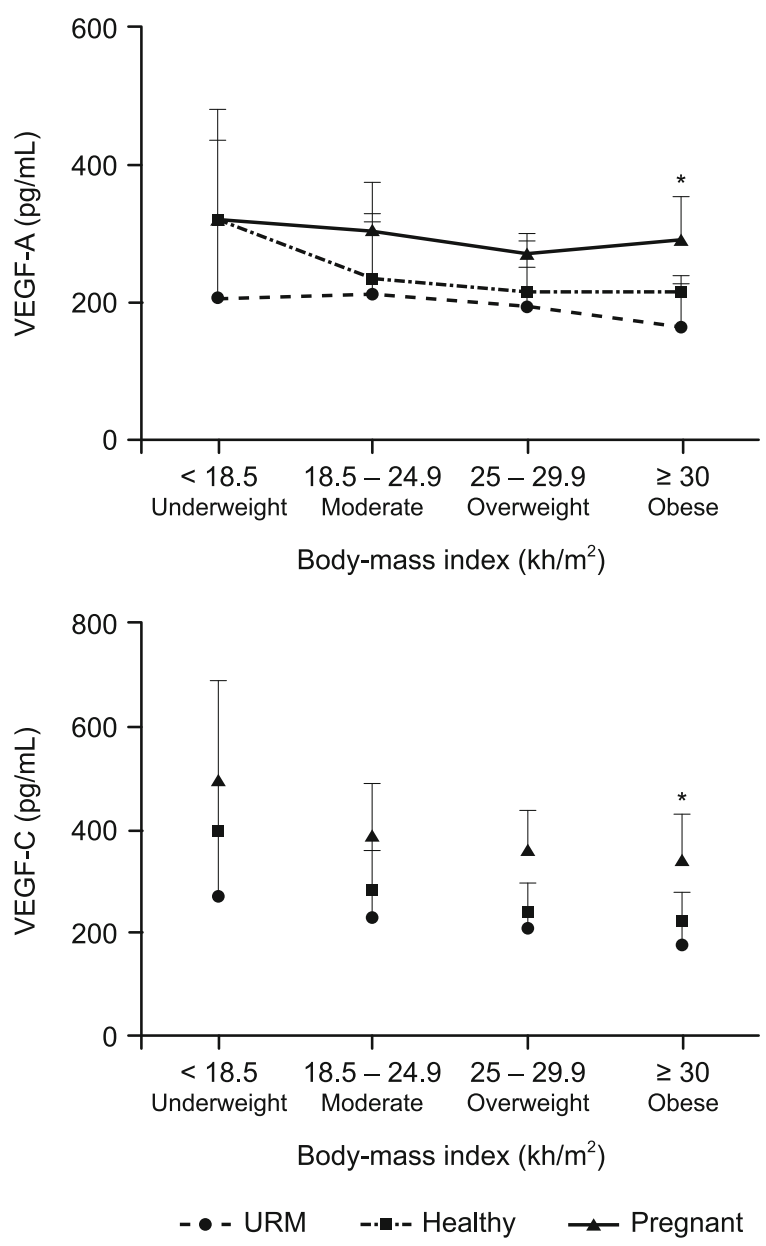

Fig. 2. Evaluation of angiogenetic factors (VEGF-A and VEGF-C) and comparing with BMI groups in women with unexplained recurrent miscarriage $(* \mathbf{p}<0.05)$. 


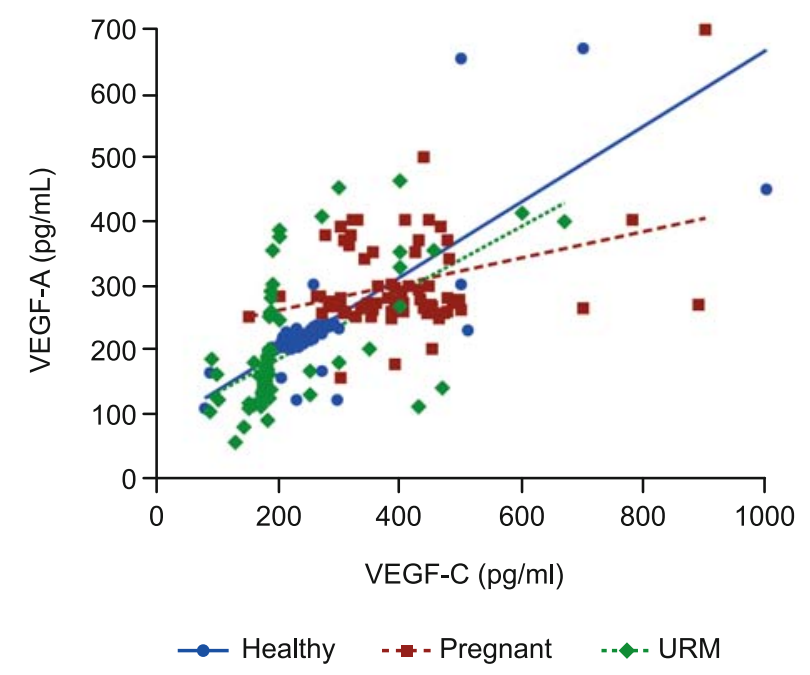

Fig. 3. Regression of VEGF-A and VEGF-C in patients and comparing with control groups.

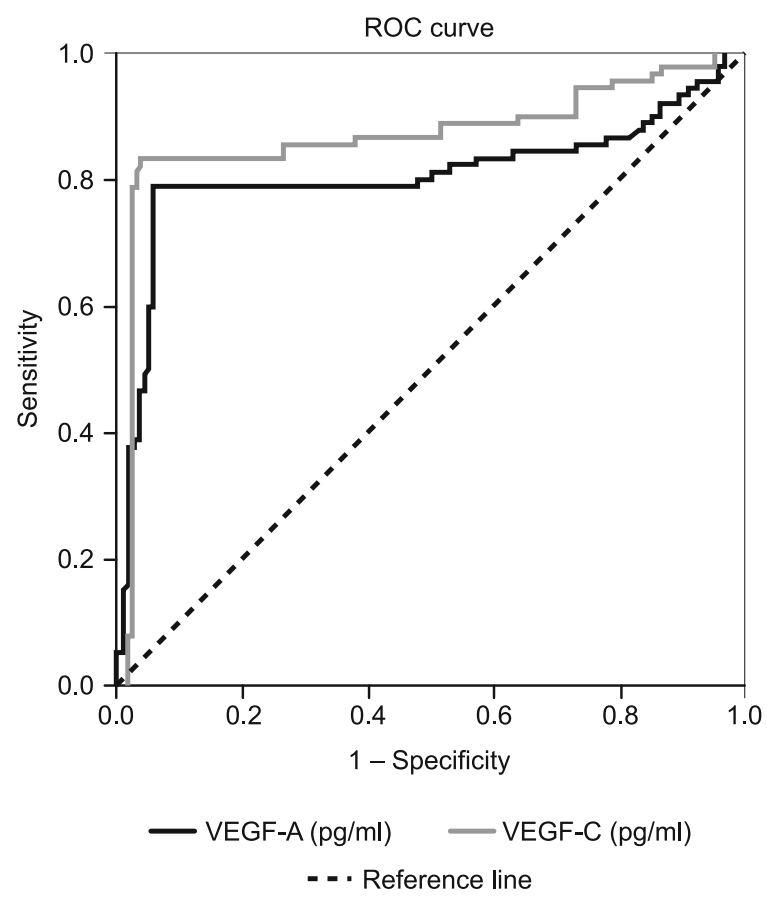

Fig. 4. ROC analysis of evaluation of serum VEGF-A and VEGF-C in unexplained recurrent miscarriage.

point is 234.8 (pg/ml) (Fig. 4). Similarly, ROC analysis in pregnant group shows the area under the curve for VEGF-A near 0.869 and cut point $250.11(\mathrm{pg} / \mathrm{ml})$ and for VEGF-C near 0.897 and cut point 289.57 (pg/ml) (Fig. 5).

\section{Discussion}

The placenta is a unique pregnancy-related tissue and plays a key role in the occurrence of unexplained recurrent pregnancy

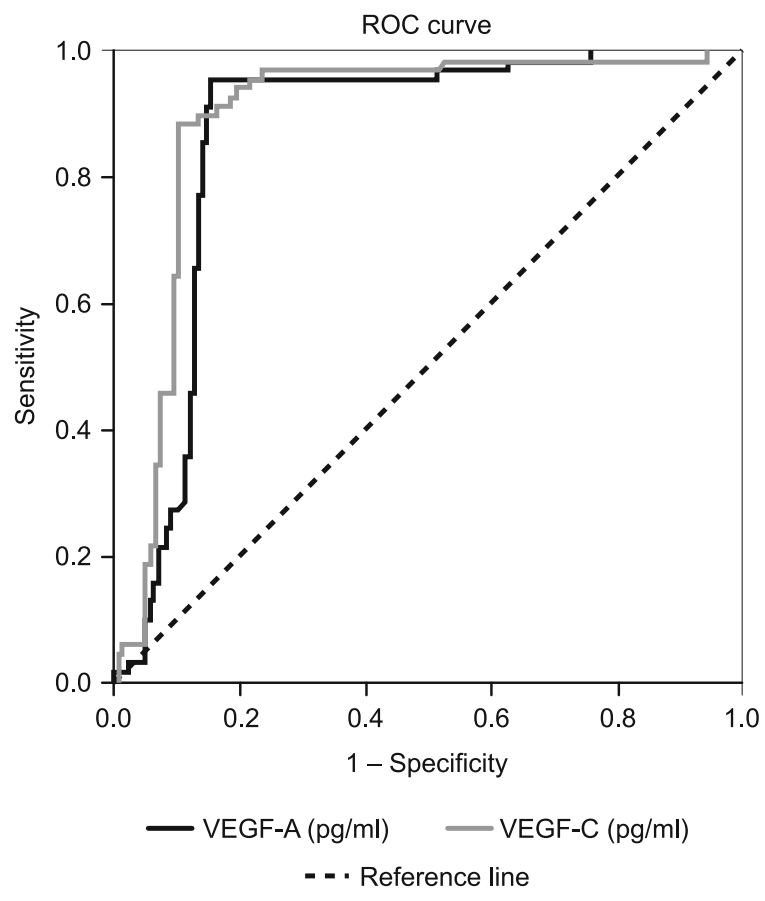

Fig. 5. ROC analysis of evaluation of serum VEGF-A and VEGF-C in pregnant women.

loss (URPL). Abnormal placentation might play a key role in the occurrence of URPL. During placentation failures, spiral artery re-modelling and angiogenesis are implicated in the pathogenesis of these complications $(21,22)$. The human placenta is rich in angiogenetic growth factors including vascular endothelial growth factor (VEGF), which plays an important role in regulation of forming placental vessels. The role of VEGF family in embryonic development, trophoblast vascularization were reported $(23,24)$.

The VEGF-A plays an important role in angiogenesis with many effects including endothelial cell proliferation, migration, increase in vascular permeability and maintenance of vessel fragility (25). VEGF-C deals with growth of blood vessels and lymphatics (26). VEGF-A and C binds with a high affinity to two related receptor tyrosine kinases expressed on vascular endothelial cells (27). The previous study showed the role of VEGF-A and VEGF-C in implantation and placentation $(28,29,30)$. Also, there is evidence of the role of VEGF in recurrent miscarriage $(31,13)$.

This study showed that maternal levels of VEGF-A and VEGF$\mathrm{C}$ were distinctly lower in URM compared to pregnant and healthy women in the control groups. Univariate analysis demonstrated that clinical characteristic factors were significantly associated with concentration of VEGF-A and VEGF-C in cases and in controls, which are known to play a relevant role in angiogenesis regulation. In the current study, we observed a lower serum concentration of angiogenetic factors and this reduction in concentration in some women with URM were 2 to 3 folds inferior to healthy women and 4 to 5 folds lower than pregnant women. Our data gave a firm support to the association between 'low expression' VEGF-A and VEGF-C susceptibility to recurrent miscarriages. 
It is proved that with increasing age, angiogenesis and biomarker change $(32,33)$. Several studies showed the negative correlation with VEGF and maternal age (34). Also, it is familiar that the risk of miscarriages increases with progressing maternal age in general population (33). However, in RM, age seems only to display a significant impact on pregnancy outcome after age 30 (19). So, it might be sufficient to undertake stratification or adjustment in multivariate analyses according to age below and above 30 years.

Obesity with its associated metabolic complications has emerged as one of the most critical healthcare problems worldwide (35). Angiogenesis is critical for adequate fat expansion and adipose tissue remodelling (36). Clinical studies showed that angiogenetic factors are blunted in human obesity, and are associated with inflammation and metabolic dysfunction (37). Tinahones, in 2009 reported, that there was a positive correlation of VEGF-A and VEGF-C with fatty acid in the obese human, however, numerous studies suggested a possible correlation between VEGF levels and human obesity (38).

Being underweight or overweight has an adverse effect on reproduction. Overweight women have a higher incidence of pregnancy complication and miscarriage (39). The prevalence of obesity in infertile women is high and some studies showed that BMI was associated with RPL (40).

By investigating the angiogenetic factors in the serum of the women with URM, this study demonstrated that the concentration of VEGF-A and VEGF-C significantly decrease with increasing Age, BMI and number of previous miscarriage. This supports the hypotheses and suggests VEGF-A and VEGF-C as a principle angiogenesis factors. These highly investigated factors are under the clinical characteristic of patient, thereby regulating embryo implantation and causing a successful pregnancy. In additional, the VEGF-A level has shown the same pattern of decreased concentration as the VEGF-C.

In conclusion, the results of the present study showed that alteration in the expression of proteins involved in proliferation and migration of endothelial cells as well as control of coagulation by these cells might played an important role in the pathogenesis of URPL. This study confirms that the cycling endometrium is a highly angiogenetic tissue and that this process is likely to be altered in women with a history of URM and may contribute to the aetiology of this condition.

Our data gave a firm support to the association between 'low expression' VEGF-A and VEGF-C susceptibility to recurrent miscarriages. Our findings suggested that these molecules could be used as potential predictive markers of miscarriage in these women presenting with URM. Thus, in URM, diagnostic and therapeutic measures aimed at characterizing and modulating other angiogenetic factors appear promising in the future.

\section{Conclusion}

The results of the present study showed that alteration in the expression of VEGF-A and VEGF-C involved in proliferation of placenta and implantation and as well as clinical characteristic such as age, BMI, and pervious miscarriage might play an important role in the pathogenesis of URM. Though, the present study introduces new proteins that might be used as diagnostic markers and might also be beneficial in therapy of URM, repeating this study with a larger sample size is recommended.

\section{References}

1. Torry D S et al. Angiogenesis in implantation. J. Assist. Reprod. Genet. 24, 303-315 (2007).

2. Saito S, Nakashima A, Shima T, Ito M. Th1/Th2/Th17 and Regulatory T-Cell Paradigm in Pregnancy. Am J Reprod Immunol 2010; 63: 601-610.

3. Hastings J M, Fazleabas AT. A baboon model for endometriosis: implications for fertility. Reprod Biol Endocrinol 2006; 4 (Suppl 1): S7.

4. Quenby $S$ et al. Uterine natural killer cells and angiogenesis in recurrent reproductive failure. Hum Reprod 2009; 24: 45-54.

5. Medicine PC of the A. S. for R. Definitions of infertility and recurrent pregnancy loss: a committee opinion. Fertil Steril 2013; 99: 63.

6. Rai R, Regan L. Recurrent miscarriage. Lancet 2006; 368: 601-611.

7. Kaandorp SP et al. Time to conception and time to live birth in women with unexplained recurrent miscarriage. Hum Reprod2014; 29: 1146-1152.

8. Duckitt K, Qureshi A. Recurrent miscarriage. BMJ Clin Evid 2011; 1409.

9. Kiprov DD et al. The use of intravenous immunoglobulin in recurrent pregnancy loss associated with combined alloimmune and autoimmune abnormalities. Am J Reprod Immunol 1996; 36: 228-234.

10. Rafi A, Devaki R, Sabitha K, Mohanty S, Rao P. Importance of Serum Copper and Vascular Endothelial Growth Factor (VEGF-A) Levels in Postmenopausal Bleeding. Indian J Clin Biochem 2013; 28: 147-151.

11. Kim M et al. VEGF-A regulated by progesterone governs uterine angiogenesis and vascular remodelling during pregnancy. EMBO Mol Med 2013; 5: 1415-1430.

12. Kikuchi R et al. An antiangiogenic isoform of VEGF-A contributes to impaired vascularization in peripheral artery disease. Nat Med 2014; 20: 1464-1471.

13. Bagheri A, Chianeh Y, Kumar P, Rao P. Angiogenic factors in relation to embryo implantation. Int J Reprod Contracept Obstet Gynecol 2014; 3: 872 .

14. Lash GE et al. Localization of angiogenic growth factors and their receptors in the human endometrium throughout the menstrual cycle and in recurrent miscarriage. Hum Reprod 2012; 27: 183-195.

15. Su MT, Lin SH, Chen YC. Genetic association studies of angiogenesis- and vasoconstriction-related genes in women with recurrent pregnancy loss: a systematic review and meta-analysis. Hum Reprod Update 2011; 17: 803-812.

16. Kalkunte SS et al. Vascular endothelial growth factor C facilitates immune tolerance and endovascular activity of human uterine NK cells at the maternal-fetal interface. J Immunol 2009; 182: 4085-4092.

17. Bagheri A, Chianeh Y, Rao P. Role of angiogenic factors in recurrent pregnancy loss. Int J Reprod Contracept Obstet Gynecol 2013; 2: 497.

18. Kupka M et al. Previous miscarriages influence IVF and intracytoplasmatic sperm injection pregnancy outcome. Reprod Biomed Online 2004; 8: 349-357. 


\section{$258-264$}

19. Garrisi JG et al. Effect of infertility, maternal age, and number of previous miscarriages on the outcome of preimplantation genetic diagnosis for idiopathic recurrent pregnancy loss. Fertil Steril 2009; 92: 288-295.

20. Lashen H, Fear K, Sturdee DW. Obesity is associated with increased risk of first trimester and recurrent miscarriage: Matched case-control study. Hum Reprod 2004; 19: 1644-1646.

21. Rehman KS, Yin S, Mayhew BA, Word RA, Rainey WE. Human myometrial adaptation to pregnancy: cDNA microarray gene expression pro ling of myometrium from non-pregnant and pregnant women. 2003; 9: $681-700$.

22. Ball E, Bulmer JN, Ayis S, Lyall F, Robson SC. Late sporadic miscarriage is associated with abnormalities in spiral artery transformation and trophoblast invasion. 2006; 535-542. doi:10.1002/path.1927

23. Vuorela P, Carpén O, Tulppala M, Halmesmäki E. VEGF, its receptors and the tie receptors in recurrent miscarriage. Mol Hum Reprod 2000; 6: 276-282.

24. Al-Khateeb GM, Mustafa FE, Sater MS, Almawi WY. Effect of the functional VEGFA-583C/T variant on vascular endothelial growth factor levels and the risk of recurrent spontaneous miscarriage. Fertil Steril 2011; 95: 2471-2473.

25. Hiratsuka $S$ et al. Vascular endothelial growth factor A (VEGF-A) is involved in guidance of VEGF receptor-positive cells to the anterior portion of early embryos. Mol Cell Biol 2005; 25: 355-363.

26. Shin JW, Huggenberger R, Detmar M. Transcriptional profiling of VEGF-A and VEGF-C target genes in lymphatic endothelium reveals endothelial-specific molecule-1 as a novel mediator of lymphangiogenesis. Blood 2008; 112: 2318-2326.

27. Lash GE et al. Localization of angiogenic growth factors and their receptors in the human endometrium throughout the menstrual cycle and in recurrent miscarriage. Hum Reprod 2012; 27: 183-195.

28. Shemesh A et al. First Trimester Pregnancy Loss and the Expression of Alternatively Spliced NKp30 Isoforms in Maternal Blood and Placental Tissue. Front Immunol 2015; 6: 189.
29. Wathén KA, Stenman UH, Leinonen E, Andersson S, Vuorela P. Concentrations of vascular endothelial growth factor $\mathrm{C}$ and $\mathrm{D}$ in amniotic fluid and maternal plasma. Acta Obstet Gynecol Scand 2009; 88: 629-634.

30. Luchin F, Wong T, Flint Porter JRS. Immunotherapy for recurrent miscarriage. Cochrane database Syst Rev 2014; 1-63.

31. Banerjee $\mathbf{P}$ et al. Identification of key contributory factors responsible for vascular dysfunction in idiopathic recurrent spontaneous miscarriage. PLoS One 2013; 8: 1-9.

32. Rivard A et al. Age-Dependent Impairment of Angiogenesis. 1999; 111-121.

33. Churchill AJ et al. VEGF polymorphisms are associated with neovascular age-related macular degeneration. Hum Mol Genet 2006; 15 : 2955-2961.

34. Gotsch $\mathbf{F}$ et al. Preeclampsia and small-for-gestational age are associated with decreased concentrations of a factor involved in angiogenesis: soluble Tie-2. J Matern Fetal Neonatal Med 2008; 21: 389-402.

35. Varma MC et al. Metabolic endotoxaemia in childhood obesity. BMC Obes $2015 ; 3: 3$.

36. Cao, Y. Science in medicine Angiogenesis modulates adipogenesis and obesity. 2007; 117.

37. Aye IL, Lager S, Ramirez VI, Gaccioli F, Dudley DJ, Jansson T, Powell TL. Increasing maternal body mass index is associated with systemic inflammation in the mother and the activation of distinct placental inflammatory pathways. Biol Reprod 2014; 90: 129.

38. Mayas D et al. VEGF Gene Expression in Adult Human Thymus Fat: A Correlative Study with Hypoxic Induced Factor 2009; 4.

39. Maheshwari A, Stofberg L, Bhattacharya S. Effect of overweight and obesity on assisted reproductive technology - A systematic review. Hum Reprod Update 2007; 13: 433-444.

40. Metwally M, Saravelos SH, Ledger WL, Li TC. Body mass index and risk of miscarriage in women with recurrent miscarriage. Fertil Steril 2010; 94: 290-295. 